\title{
Qualitative study of HIV related stigma and discrimination: What women say in Iran
}

\author{
Fatemeh Oskouie ${ }^{1}$, Farzaneh Kashefi ${ }^{2}$, Forough Rafii ${ }^{1}$, Mohammad Mehdi Gouya ${ }^{3,4}$
}

\author{
${ }^{1}$ Ph.D., Professor, Nursing Care Research Center and School of Nursing and Midwifery, Iran University of Medical \\ Sciences, Tehran, Iran \\ ${ }^{2}$ Ph.D. Student, Nursing Care Research Center, Iran University of Medical Sciences, Tehran, Iran \\ ${ }^{3}$ MD, Director General (DG), Iranian Center for Communicable Disease Control (CDC), Ministry of Health and \\ Medical Education (MOHME), Tehran, Iran \\ ${ }^{4}$ Associate Professor, School of Medicine, Iran University of Medical Sciences, Tehran, Iran
}

\section{Type of article: Original}

\begin{abstract}
Introduction: HIV-related stigma is a major social problem of people living with HIV. Stigma against these people, especially women, interferes with the prevention, diagnosis and treatment of HIV. This study examined the experiences of HIV infected women who were stigmatized, as well as the strategies used to tackle the issue.

Methods: Twenty-five women living with HIV were examined using in-depth, semi-structured interviews. The data obtained was analyzed using content analysis method in MAXQDA10.

Results: The finding of this study was classified into four themes: fear, shame, rejection by family or friends and feelings of frustration. The participant strategies adopted to the perceived stigma and discrimination included isolation, nondisclosure, and loss of follow-up.

Conclusions: HIV in women has different social interposition. It is necessary to intervene, so as to alleviate the effect of stigma on HIV infected women, in order that they gain the ability to accomplish wellness, increase life span and improve quality of life. Nurses, midwives and other professionals need to be involved to ensure public policy in providing supportive environments, and decrease stigma.
\end{abstract}

Keywords: Stigma, Discrimination, HIV, AIDS, Qualitative study

\section{Introduction}

The human immunodeficiency virus (HIV) pandemic remains a global health challenge. Today 36.9 million people in the world live with HIV (1). According to the latest published statistics, the number of people with HIV in Iran is 30,183 . Sixty- six percent $(66 \%)$ of the patients are men and thirty-four percent $(34 \%)$ are women. Today, sexual transmission rates could be increased from 10 to $41 \%$ (2). In Iran, a national HIV treatment system has been established, and is the pioneer in the Middle East for HIV prevention (free needle-exchange program) (3). During the past decade, researchers have been asked to expand the theoretical knowledge of HIV related stigma, and pay more attention to the contexts and approaches utilized (4). Despite numerous attempts aimed at its prevention and cure, HIV/AIDS is still widespread and stigmatization is still a potent barrier for HIV-positive women (5). Goffman defines stigma as "an attribute that reduces a person in the minds of others from a whole and usual person to a tainted, discounted one" (6). Based on research conducted in Iran, HIV infected women are still suffering stigma and discrimination (7). HIV stigma hinders the movement of an effectual remedy, as well as effective health results for HIV infected individuals (8). Stigmatization among these women creates numerous problems, including loneliness, isolation, low self-esteem, identity crisis, low seeking care behavior and non-participation in routine HIV testing (9). Stigma interferes with medication adherence, insufficient service utilization and eventually apathetic effects on morbidity and mortality $(10,11)$. They are faced with a charge and held aloof by their family and community because these women are alert to their HIV status. However, when women with HIV experience compassion from their community, they have the tendency to take precautions regarding their sexual behavior (5).

\section{Corresponding author:}

Farzaneh Kashefi, Nursing Care Research Center, Iran University of Medical Sciences, Rashid Yasami Street, ValiAsr Avenue, Tehran, Iran. Telefax: +982188671613, E-mail: Kashefimidwife@gmail.com, Kashefi.f@tak.iums.ac.ir Received: October 12, 2016, Accepted: February 10, 2017, Published: July 2017

iThenticate screening: January 29, 2017, English editing: March 04, 2017, Quality control: June 12, 2017

(C) 2017 The Authors. This is an open access article under the terms of the Creative Commons Attribution-NonCommercialNoDerivs License, which permits use and distribution in any medium, provided the original work is properly cited, the use is non-commercial and no modifications or adaptations are made. 
The case is so serious that it has consolidated the common knowledge that HIV stigma is to some extent adaptable by awareness, training, education and exposure (12). Experiences such as rejection by societal discrimination or disapproval, which are related to HIV, may increase the sense of shame of the infected individual based on their illness (4). These women may also gain experience in some unpleasant circumstances in their lives such as animosity, refusal of profitable employment, obligatory early retirement, and delivery of low-avidity treatment and therefore, aggregation in hospitals. Women with HIV normally experience discrimination and deprivation from a community rooted in stigma. Consequently, they prefer not to reveal their infection and continue to get involved in risky behavior (5). Although 25 years have passed since the widespread occurrence of HIV in Iran, as in other parts of the world, women have been suffering from stigmatization and discrimination, when they interact in society (13). Unfortunately, few studies have been conducted on the stigma experience of HIV infected outpatient women in Iran. The aim of this study was to reveal the voices of HIV infected women in Iran, and their experience of stigma.

\section{Material and Methods}

\subsection{Design and participants}

A qualitative research method was employed for this study. Purposeful sample of eligible participants was recruited between October 2015 and December 2016 from behavioral counseling centers affiliated to three medical universities in Iran: Iran University of Medical Sciences, Tehran University of Medical Sciences and Shahid Beheshti University of Medical Sciences in Tehran. The centers provide specific services such as medical and psychological care. Eligible participants had to have received an HIV diagnosis by lab data, at least 18 years old, and Persian speaking. Participants were granted a 300,000 Rials gift card as a token of the investigator's appreciation. Matic saturation was regarded as the base of recruiting the target numbers.

\subsection{Data Collection}

A qualitative research content analysis method was used. Due to the unfamiliar atmosphere with the women, the staff tried their best to approach them by helping them with the aim of building trust and encouraging patients to participate in the interviews. Staff and counselors who were at the centers, instructed in advance regarding the goals and methods of the study. In addition, centers physicians introduced women who were consent to participate in the study. With the aid of a purposeful sampling, 25 participants were selected. At the interview, a consent form and a brief demographic questionnaire was completed by the participants. The following questions were asked in the interview: How do you feel about the disease? How is your life influenced by the disease? The subjects of the study were asked to give their viewpoints according to their personal life experiences. Interviews were conducted in a private room in the behavioral counseling centers. Most interviews lasted for 45 to 60 min. Investigator took notes on the interviews which were also recorded after obtaining permission from interviewees. Each participant responded to questions about age, education, marital status, job, HIV status, number of children, time of diagnosis and the method of transmission. In order to find out the themes, the recorded interviews and notes were coded with MAXQDA 10 software and grouped into categories. The supervisor reviewed the transcripts of the interviews for accuracy.

\subsection{Data analysis, reliability and validity}

Data analysis used was conventional content analysis by constant comparison method. This type of design is usually appropriate when existing theory or research literature on a phenomenon is limited (15). To ensure the accuracy of the analyzed data, we used four criteria of credibility, dependency; conformability and transferability, which were used according to Lincoln and Guba (16).

\subsection{Ethical Considerations}

This study was reviewed and approved by the Ethical Committee of the Iran University of Medical sciences (IUMS) (Ethic Code: 105/5983). All participants were asked to provide consent in Persian, their free will to take part in the interview, and the entire data collected was anonymous. The transcriptions and records, in their entirety, were secured and coded in a protected file. Refusal to participate in the study had no interference with the service or treatment received at the center.

\section{Results}

Table 1 shows the demographic profile of the participants. The participants aged between 20 and 49 years old. Ten women were married, nine women were divorced, two women were widowed and four women were single. Women with HIV described four main themes of HIV- related stigma: fear, shame, rejection by family or friends and feeling frustrated. Four main themes show the approaches participants had to their personal experiences by isolation, non- 
disclosure and loss of follow-up. All the themes discussed below depict the dimensions of experiencing the stigma and the strategies employed to deal with such experiences.

\subsection{Dimension of the stigma}

The majority of the participants tried to hide their disease due to fear of death and loss of their children. The participants unanimously referred to AIDS as a fatal disease.

\subsubsection{Fear:}

Mahtab, a 32-year old described her fear of death as follows: "During the first test, I was very ill and infected with Cytomegalovirus; thereafter, I was hospitalized in ICU due to coma. I was terrified that I was going to die"...

In another example, Atena said: "I started losing weight, headache began with nausea, and vomiting, finally I decided to go to the clinic because I could see that I was dying .... I do not know when it will kill me .... I cried for days and speak to my god... I am afraid of death". Another participant said: "I started to become irritable. I was in a good mood until I began treatment. I thought my life has ended and I was afraid to die and Gandom (my daughter) will have no support. I don't want my child to be raised by another". Participants were scared of permanent disabilities. "I was afraid of change and being crippled". When they told me, if treated I would not change and stay well, I felt like I could keep my dignity. My self-esteem was improved. I had a bad feeling during a month of struggling "(Rogin, a 42-year-old). "I now have an 18-year-old daughter but I can never say that I use these treatments because of this disease. It is a very awkward and scary feeling because if our child was aware of the fact that her parents are infected with this virus she may avoid us" (Mahan, 38 years-old afraid of being discriminated by her daughter). The participants described stigma as the unforeseen or anticipated fear of how other people would respond to HIV infected women. Clearly, Mahan feared that the stigma she is experiencing would be transferred to her daughter.

\subsubsection{Shame:}

Being HIV positive confers to a strong sense of shame, with the family also feeling the disgrace. Even though the family provides good care, the true compassion is not seen, if ever mentioned (10). The stigma and fear of how HIV women would reveal their HIV status, was regularly stated as a response to every question. It was reported that women living with HIV expressed a sense of shame. They also stated that not only people will know about the disease, but they are also disturbed by the gossip and how people talk. People might think that the disease is transmitted by drug injections or unwanted sexual behavior. Especially if the patient is a woman, they think that she probably could have gotten the disease from disapproved sexual intercourse and if the patient is a man, they think the transmission route was via injecting drugs. "This disease is not acceptable in terms of our traditions. Well, people have different attitude towards us which is hard to deal with (silence)" (Araks, 34 years-old). Another participant said, "People think badly of this disease, most of the people prefer to claim that they have been infected by drug injection rather than having sex" (Maral, 32 years old). "I may live for as long as a normal person, but I am like a person in death row waiting to be executed. Our society has a different attitude towards us. Fortunately, there are not many people here so I feel comfortable coming, however before now, when the center was located somewhere else, it was full of people and I did not feel comfortable coming. I do not like this; the attitude of people is such that when they know why you are here, you feel ashamed" (Elham, 37 year-old).

\subsubsection{Rejection}

In our study, most people had been abandoned by their family and society. According to their experiences, education and awareness of people is very low, therefore after informing the family about the disease, some reacted very badly or even rejected these people. "They said we would not interact with such people, if we knew someone was suffering from AIDS, we would leave them" (Elnaz 32-year-old). "You may enter a place where people do not behave well towards you or point at you. The only thing that has made this disease such a monster is the thought of sexual intercourse. So you are abandoned unintentionally. One of my friends said when she approached his 80 -yearold father to kiss him; he avoided the kiss due to lack of knowledge" (Rogin 42 years old). "I have heard the discussions over and over that you should not be friends with someone infected with HIV as she might infect you. Interestingly, I heard it from someone with a master degree from a university "(28-year-old participant). "I lost my job because of this disease. I used to work in a barbershop. I lost my abilities and so I was forced to talk about my disease with my boss and she asked me to resign. This disease has not been resolved for at least $80 \%$ of the people, and they think they will be infected by hand contact or kissing. My boss did not even allow me to pour tea in his cup soon after she discovered that I have HIV. My sister also worked there and my boss forced her to take the test even though I insisted that she is my sister and there is no way she could have been infected with the disease. Nevertheless, she insisted that my sister eats with me and even though I told him it's not a route of transmission, she would just not understand. My sister had to take the test so that she would not lose her job. The name of the disease causes fear. We have a dentist neighbor, whom my husband once went to for dental care, and was told about the 
disease for clear conscious but she informed the whole building that we live in. I once heard the building supervisor saying to another suite, do not keep close contact with them, they have such disease. If you tell people that someone has cancer they will hug and kiss him and protect him financially but they have such bad attitude towards us (with anger). Leave them alone, that is what they say we did not contract this disease intentionally. It is just out of ignorance; we are patients like someone with cancer "(44-year-old participant describing her experience).

\subsubsection{Frustration:}

According to the participants, most of them feel frustrated and lonely. One participant said "most of the time I just sit by myself talking to myself saying why? Why me?" Another participant mentioned how it would have been better to have another disease. More than half of the women believed that it would have been better to have cancer than HIV, "At least people will show some compassion there" "When I think about it, it is kind of hard to take. I may sometimes think it is very easy but (along with sadness and crying) I did not deserve this. I have done nothing bad in my life. I do not know .... (Silence), but how long am I going to be isolated and not talk about my problems? How long can I stand being mocked or being called a HIV-positive patient? (Along with crying)" (Elnaz, 32 yearold). Azita, a 33-year-old who got married for the second time to an addict, talked about her experience; "I always asked why this happened to me. Why I did this. Why I did not investigate about my husband. Damn me, why did I not ask his neighbors, but then I said to myself maybe it is my destiny (with sadness)".

\subsection{Strategies Adopted with Stigma}

The strategies adopted include isolation, non-disclosure and loss of follow-up. Women living with HIV/AIDS may prefer to stay isolated rather than facing the stigma. Most participants in this study found that although secrecy protected them from rejection and pain, it also led to isolation. They had to make excuses to refrain from seeing old friends, and making new friends.

\subsubsection{Isolation:}

Fataneh, 44 years old said, "I was isolated after being infected. I lost my job because of this disease. My boss normally tells me to come and visit them but when I did, she told me not to shake hands with others. They do not understand but he told me not to shake hands or kiss them so I stopped visiting". Another participant said, "As soon as I found out about my disease, I tried not to communicate with others as we are a big family and we used to communicate a lot. Some participants decided not to attend any public events, like weddings, birthdays and family reunions." Elnaz a self- isolated patient stated that, when she discovered that she was HIV-positive, she gave up participating in any feasts, she did not wish to visit anybody including her own sister.

\subsubsection{Nondisclosure:}

Several participants were not able to communicate with honesty and effectiveness with other people as they were afraid of negative retribution regarding past negative experiences. The subjects of this study felt that other people are scared of being infected and therefore denied verbally and emotionally. Mahan said, "One day I went to a dental clinic, they gave me a form to state if I had any special disease, I wrote about my disease but they did not provide me with any services and I was dying of pain, I was there for my wisdom tooth. I had a terrible pain in my whole body and it was hard to keep on living. I visited two other places and they reacted the same way. I was even ready to pay more so that they would do something for me, which they did not. Thereafter, I went to a doctor and this time around, I did not write about my disease and I simply got the service I wanted. I literally said I would never inform anybody about my disease and my husband agreed to it. Do not write about your disease, they will not provide you with any services, pain was killing me, tolerating that much pain was difficult." Another participant who was a housekeeper explained that she went to the hospital for urinary tract infection; "She could not even inform her sister and family because they could find out about her disease, she had to hide her disease". Another participant said, "Healthcare professionals do not have a good attitude towards us. Physicians, dentists or laboratory technicians will not treat us well. Some of them behave in such a way that we will regret even seeking medical help. Azita, a 33year-old participant and a housekeeper explained, "When I was an expectant mother, I went to a hospital where I was referred to a gynecologist, in that ward, every doctor passed me to another and I was just crying as people asked me if I had lost someone. From that time, I promised myself not to tell anyone (angry and throwing her purse). I told them you would wear gloves how can I transmit the virus to you? What kind of attitude is that? They all screamed out to one another to visit me (angry and crying). I was hearing them, I think nobody saw me in the end and told me we have no time, when I came out I told my husband that I will never talk about my disease, why do I have to cry this much? I would never say that I am infected with HIV anywhere else. Yes, I have this bad memory and when I went to visit a dentist, I did not talk about my disease. It has been 2-3 years since I last visited the hospital for a midwifery control". 


\subsubsection{Loss of follow-up:}

Fear of disclosure affected the process of treatment in many women due to the fact that they did not want to take their medication in the presence of others. The result of nondisclosure caused changes related with the ability of women. The participants in our study were hesitant to inform anyone for fear of been rejected. The HIV related stigma is a more serious problem for women. Mahsa key informants stated that the main motive for the withdrawal of women with HIV from follow-up was stigma. Most participants in this study prefer not to show up in society or hospital, so they continue with self-medication or alternative therapies.

Table 1. Demographic Profile of Participants

\begin{tabular}{|l|l|l|}
\hline \multicolumn{2}{|l|}{ Characteristics } & n (\%) \\
\hline Age (year), mean (SD) & Less than high school & $35(1.4)$ \\
\hline \multirow{4}{*}{ Education } & High school & $14(56)$ \\
\cline { 2 - 3 } & More than high school & $5(20)$ \\
\hline \multirow{5}{*}{ Relationship status } & Single & $6(24)$ \\
\cline { 2 - 3 } & Married & $4(16)$ \\
\cline { 2 - 3 } & Divorced & $10(40)$ \\
\cline { 2 - 3 } & Widow & $9(36)$ \\
\cline { 2 - 3 } & Separated & $1(4)$ \\
\hline \multirow{5}{*}{ Employment status } & Full time & $1(4)$ \\
\cline { 2 - 3 } & Part time & $4(16)$ \\
\cline { 2 - 3 } & No employment & $4(16)$ \\
\hline \multirow{5}{*}{ Risk factor for acquiring HIV HIV diagnosis } & +6 years ago & $17(68)$ \\
\cline { 2 - 3 } & 4-6 years ago & $3(12)$ \\
\cline { 2 - 3 } & 1-3 years ago & $6(24)$ \\
\cline { 2 - 3 } & Sexual contact & $16(64)$ \\
\cline { 2 - 3 } & Intravenous drug user & $4(16)$ \\
\cline { 2 - 3 } & Both of them & $3(16)$ \\
\cline { 2 - 3 } & Partner's intravenous drug use & $12(48)$ \\
\cline { 2 - 3 } & Unknown & $2(8)$ \\
\hline
\end{tabular}

$\mathrm{SD}=$ standard deviation

\section{Discussion}

The 25 women who participated in our study had various experiences, not only related to stigma but also to situations where they lived. In major parts of the globe, women lack the social, economic, and will that men have, and this makes them prone to HIV and other negative aspects of life. Stigma might have critical unfavorable effects on the daily lives of women due to the fact that it leads to a lack of control over sexuality (17). Women had the experience of feeling at loss which gave rise to the feeling of fright and shame that they had been diagnosed with HIV. This experience, in turn, resulted in coping in the form of social isolation, which is self-imposed, and secrecy about their health condition. Feeling ashamed facilitated the internalization of negative realization, and culminated in more profound forms of self-discrimination (18). This study found that the fear of stigmatization in women did not vanish, even after they began treatment. However, some of them refrained from visiting support groups, which are available at the centers. Therefore, they prefer to receive care from centers far from their residence or use selfmedication and alternative therapies. Previous studies indicate that a minority of participants stated that people behave negatively towards them (42\%), avoid being close to them (29\%) or are ostracized from social events $(20 \%)$, because of their HIV status. This study revealed that HIV related stigma is still the main concern. Endeavors to decrease stigma are necessary to focus prompt HIV relevant test and treatment. Strong stigma towards women with HIV is due to the fright of transmission and immoral behavior $(19,20)$. Shame was greatly observed in women with HIV, a finding discovered in the current studies conducted in Kuwait and Saudi Arabia, which enjoy common culture and religious backgrounds with Egypt (20). The stigma of carrying HIV and associated discrimination, has to be ended through specific cultural programs. The programs need to emphasize on value-based stigma and link the cultural norms of $t$ society, gender and ethical debates to talk about the stigma. It has been shown that the utilization of interventions that bring HIV positive women and other people together in face-to-face interactions, can successfully decline the concept of shame in women with HIV (21). Participants in the present study encountered a great deal of stigma when ever they visited a dentist, which was in line with previous studies (13). Social support, 
which has been readily available most times in their lives, would now be useful in dealing with this disease. If women choose to keep their test results secret, they must avoid any situation where they may have to reveal their diagnosis. According to the women in this study, the most serious impact of non-disclosure is isolation. They believe this isolation is necessary if they choose to be less than honest with others. Their decision to reveal their test results to everyone may lead to rejection, frustration and pain. Some subjects revealed that they stayed away from family and friends in order not to be rejected (13). Discrimination deprived them of having success to others which made them feel ashamed and concealed their problem. Disclosure could be a way of gaining care and support (22, 23). Updated programs and researches with profound religious values are supplemented by the Iran AIDS program; nevertheless, HIV positive women in Iran are greatly faced with embarrassment and isolation, and usually do not seek medical care in a scheduled program. The present study provides precious insight into stigma prevention, which has been depicted to change because of intervention. Moreover, clergymen can plan supportive interventions to develop anti-stigma programs. Religious leaders should be motivated to talk about acceptance and coping of those living with HIV.

\section{Limitations}

Since these findings are from a qualitative research design, they lack generalizability. The entire population of this study were recruited from the behavioral counseling centers of Tehran. Therefore, the stigma experienced by our participants might have been different from those attending other clinics. This does not allow generalizing the results to the entire population of HIV-positive women in Iran. Despite these limitations, we believe that this study possesses several strengths. This research was the first of its kind in Iran that investigated the magnitude of HIVrelated stigma and discrimination against women. Further to this, we used in-depth interviews that allowed us explore the participants' feelings and perspectives on HIV-related stigma. The one-on-one interviews were productive as each participant had enough time and opportunity to share her feelings, perspectives and attitudes. Since participants tended to express themselves more freely, the researcher had enough time to probe and obtain indepth responses. Findings of our study have important implications for practice, and can help improve the services and interventions for HIV-positive women that in turn, reduce the HIV-related stigma among these people.

\section{Conclusions}

The findings of this study showed stigma toward these women. This study showed that it is necessary to pay closer attention to women with much experience of living with HIV, and utilizing the obtained experiences to gain more profound knowledge of the issue as a whole. With regard to recent theoretical perspectives, the study of stigma related HIV sounds useful. It is necessary for authorities to consider HIV and the program for health education in

varied local communities of Iran. Training people to enhance their understanding on the transmission and control of HIV is significant in tackling the problem.

\section{Acknowledgments:}

The data were collected as part of a Ph.D. degree dissertation at the Nursing Care Research Center in Iran University of Medical Sciences. The authors would like to express their gratitude to the Health Departments of Iran University of Medical Sciences, Tehran University of Medical Sciences and Shahid Behshti University of Medical Sciences for their support and contribution to this study. Also, we would like to note our appreciation of the women, who took part in this study, for their valuable contribution. They voluntarily participated in the study and shared their thoughts and experiences. Without their cooperation, the present study would have not been possible.

Note: All names in the text are pseudonyms.

\section{Conflict of Interest:}

There is no conflict of interest to be declared.

\section{Authors' contributions:}

FK wrote the proposal, conducted data collection and analysis and wrote the draft manuscript. FO contributed toward the conceptualization of the study, interpretation of the finding and drafting of the manuscript. All authors have given final approval of the version to be published.

\section{References:}

1) World Health Organization. Available from: http://www.who.int/mediacentre/factsheets/fs360/en/2015.

2) Center for control disease. Ministry of Health and Medical Education of Islamic Republic of Iran, 2015. 
3) Rahmati-Najarkolaei F, Niknami S, Aminshokravi F, Bazargan M, Ahmadi F, Hadjizadeh E, et al. Experiences of stigma in healthcare settings among adults living with HIV in the Islamic Republic of Iran. J Inte AIDS Soc. 2010; 13(1): 27. doi: 10.1186/1758-2652-13-27. PMID: 20649967, PMCID: PMC2919446.

4) Vanable PA, Carey MP, Blair DC, Littlewood RA. Impact of HIV-related stigma on health behaviors and psychological adjustment among HIV-positive men and women. AIDS Behav. 2006; 10(5): 473-82. doi: 1007/s10461-006-9099-1. PMID: 16604295, PMCID: PMC2566551.

5) Dahlui M, Azahar N, Bulgiba A, Zaki R, Oche OM, Adekunjo FO, et al. HIV/AIDS Related Stigma and Discrimination against PLWHA in Nigerian Population. PLoS one. 2015; 10(12): e0143749. doi: 10.1371/journal.pone.0143749. PMID: 26658767, PMCID: PMC4675522.

6) Goffman E. Stigma: Notes on a spoiled identity. Jenkins, JH \& Carpenter; 1963.

7) Seyed Alinaghi S, Paydary K, Kazerooni PA, Hosseini M, Sedaghat A, Emamzadeh-Fard S, et al. Evaluation of Stigma Index Among People Living With HIV/AIDS (PLWHA) in Six Cities in Iran. Thrita. 2013; 2(4): 69-75. doi: 10.5812/thrita.11801.

8) Gagnon M. Re-thinking HIV-Related Stigma in Health Care Settings: A Qualitative Study. J Assoc Nurses AIDS Care. 2015; 26(6): 703-19. doi: 10.1016/j.jana.2015.07.005. PMID: 26300466.

9) Simbayi LC, Kalichman S, Strebel A, Cloete A, Henda N, Mqeketo A. Internalized stigma, discrimination, and depression among men and women living with HIV/AIDS in Cape Town, South Africa. Soc Sci Med. 2007; 64(9): 1823-31. doi: 10.1016/j.socscimed.2007.01.006. PMID: 17337318, PMCID: PMC4271649.

10) Duffy L. Suffering, shame, and silence: The stigma of HIV/AIDS. J Assoc Nurses AIDS Care. 2005; 16(1): 13-20. doi: 10.1016/j.jana.2004.11.002. PMID: 15903274.

11) Rao D, Feldman BJ, Fredericksen RJ, Crane PK, Simoni JM, Kitahata MM, et al. A structural equation model of HIV-related stigma, depressive symptoms, and medication adherence. AIDS Behav. 2012; 16(3): 711-6. doi: 10.1007/s10461-011-9915-0. PMID: 21380495.

12) Parker R, Aggleton P. HIV and AIDS-related stigma and discrimination: a conceptual framework and implications for action. Soc Sci Med. 2003; 57(1): 13-24. PMID: 12753813.

13) Karamouzian M, Akbari M, Haghdoost AA, Setayesh H, Zolala F. "I am dead to them": HIV-related stigma experienced by people living with HIV in Kerman, Iran. J Assoc Nurses AIDS Care. 2015; 26(1): 46-56. doi: 10.1016/j.jana.2014.04.005. PMID: 24856436.

14) Graneheim UH, Lundman B. Qualitative content analysis in nursing research: concepts, procedures and measures to achieve trustworthiness. Nurse Educ Today. 2004; 24(2): 105-12. doi: 10.1016/j.nedt.2003.10.001. PMID: 14769454.

15) Hsieh HF, Shannon SE. Three approaches to qualitative content analysis. Qual Health Res. 2005; 15(9): 1277-88. doi: 10.1177/1049732305276687. PMID: 16204405.

16) Guba EG, Lincoln YS. Competing paradigms in qualitative research. Handbook of qualitative research. 1994; 2(163-194): 105.

17) Lentine D, Hersey JC, Iannacchione V, Laird G, McClamroch K, Thalji L. HIV-related knowledge and stigma-United States, 2000. Morbidity and Mortality Weekly Report. 2000; 49(47): 1062-4.

18) Saki M, Kermanshahi SMK, Mohammadi E, Mohraz M. Perception of Patients With HIV/AIDS From Stigma and Discrimination. Iran Red Crescent Med J. 2015; 17(6): e23638. doi: 10.5812/ircmj.23638v2. PMID: 26290751, PMCID: PMC4537784.

19) Abdi IA, Ereg D, Ali M, Rahlenbeck SI. Knowledge and Attitudes about AIDS/HIV in a semi-nomadic population in Somaliland. J community health. 2013; 38(2): 246-9. doi: 10.1007/s10900-012-9606-4. PMID: 23014800.

20) Lohiniva AL, Benkirane M, Numair T, Mahdy A, Saleh H, Zahran A, et al. HIV stigma intervention in a low-HIV prevalence setting: a pilot study in an Egyptian healthcare facility. AIDS care. 2016; 28(5): 64452. doi: 10.1080/09540121.2015.1124974. PMID: 26717980.

21) Nyblade L, Jain A, Benkirane M, Li L, Lohiniva AL, McLean R, et al. A brief, standardized tool for measuring HIV-related stigma among health facility staff: results of field testing in China, Dominica, Egypt, Kenya, Puerto Rico and St. Christopher \& Nevis. J int AIDS Soc. 2013; 16(3). doi: 10.7448/IAS.16.3.18718. PMID: 24242266, PMCID: PMC3833189.

22) Lekganyane R, du Plessis G. Dealing with HIV-related stigma: a qualitative study of women outpatients from the Chris Hani Baragwanath Hospital. J Assoc Nurses AIDS Care. 2012; 23(2): 155-62. doi: 10.1016/j.jana.2011.05.003. PMID: 21715188.

23) Norman A, Chopra M, Kadiyala S. HIV disclosure in South Africa: Enabling the gateway to effective response. Renewal working paper. International Food Policy Research Institute. 2005. 